
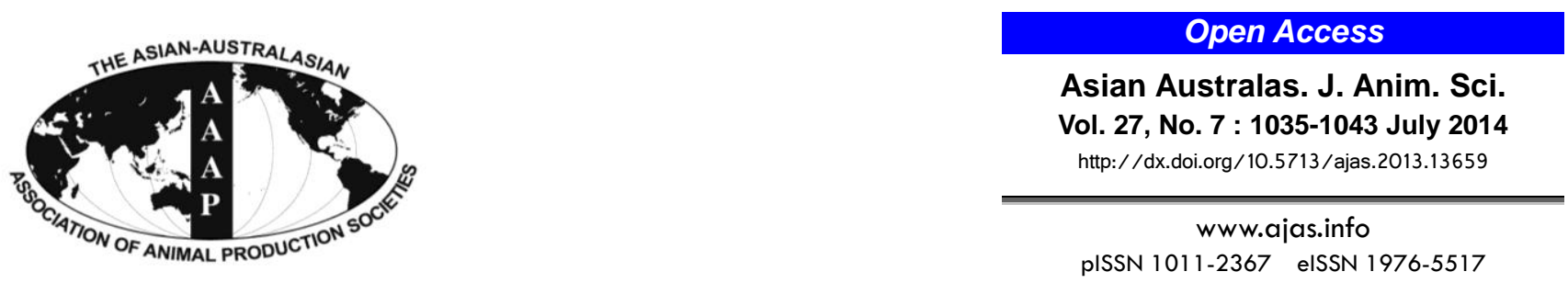

\title{
Effects of Acanthopanax senticosus Polysaccharide Supplementation on Growth Performance, Immunity, Blood Parameters and Expression of Pro-inflammatory Cytokines Genes in Challenged Weaned Piglets
}

\author{
Jie Han, Lianquan Bian*, Xianjun Liu, Fei Zhang, Yiran Zhang, and Ning Yu ${ }^{1}$ \\ College of Animal Science and Veterinary Science, Shenyang Agricultural University, Shenyang 110-866, China
}

\begin{abstract}
To investigate the effect of dietary Acanthopanax senticosus polysaccharide (ASPS) on growth performance, immunity, blood parameters and mRNA expression of pro-inflammatory cytokines in immunologically challenged piglets, an experiment employing $2 \times 2$ factorial arrangement concerning dietary ASPS treatment $(0$ or $800 \mathrm{mg} / \mathrm{kg})$ and immunological challenge (lipopolysaccharide [LPS] or saline injection) was conducted with 64 crossbred piglets (weaned at $28 \mathrm{~d}$ of age, average initial body weight of $7.25 \pm 0.21 \mathrm{~kg}$ ) assigned to two dietary ASPS treatments with 8 replicates of 4 pigs each. Half of the piglets of per dietary treatment were injected with LPS or saline on d 14. Blood samples were obtained at $3 \mathrm{~h}$ after immunological injection on $\mathrm{d} 14$ and piglets were slaughtered to obtain spleen samples on d 21. Dietary ASPS did not affect average daily gain (ADG) $(p=0.634)$, average daily feed intake $(A D F I)(p=0.655)$, and gain:feed $(p=0.814)$ prior to LPS challenge. After LPS challenge, for LPS-challenged pigs those fed ASPS had higher ADG and ADFI than the non-supplemented group $(\mathrm{p}<0.05)$, and an interaction between LPS $\times$ ASPS was observed on the two indices $(\mathrm{p}<0.05)$. Dietary ASPS improved lymphocyte proliferation among saline-injected and LPS-injected pigs $(p<0.05)$. Interaction between LPS $\times$ ASPS was also revealed on lymphocyte proliferation $(p<0.05)$. Circulatory concentration of $\operatorname{IgG}$ was influenced neither by ASPS $(\mathrm{p}=0.803)$ or LPS $(\mathrm{p}=0.692)$, nor their interaction $(\mathrm{p}=0.289)$. Plasma concentration and spleen mRNA expression of interleukin-1beta (IL-1 $\beta$ ), interleukin-6 (IL-6), and tumor necrosis factor (TNF)- $\alpha$ were induced to increase $(\mathrm{p}<0.05)$ by LPS challenge, in contrast, these indices were decreased by dietary ASPS $(p<0.05)$, and interactions were found on these cytokines $(p<0.05)$. For LPS-challenged pigs, dietary ASPS also reduced the circulating concentration and spleen mRNA expression of IL-1 $\beta$, IL-6 as well as TNF- $\alpha(p<0.05)$. The interaction between LPS $\times$ ASPS was also observed on the circulating concentration of insulin-like growth factor- I, $\alpha$-acid glycoprotein $(\alpha$-AGP), nonesterified fatty acid, and glucose $(p<0.05)$. The results of this study demonstrate that dietary ASPS can modulate the release of pro-inflammatory cytokines during immunological challenge, which might enable piglets to achieve better growth performance. (Key Words: Herbal Extract, Stress, Growth, Cytokines, Metabolism, Weaned Pigs)
\end{abstract}

\section{INTRODUCTION}

The process of weaning involving complex psychological, social, environmental and dietary stressors is one of the most stressful events in pig's life and can contribute to serial pathogenic and nonpathogenic immunological challenge (Blecha and Charley, 1990;

\footnotetext{
* Corresponding Author: Lianquan Bian. Tel: +86-24-8841-0865, Fax: +86-24-8841-0865, E-mail: bianlq@163.com

${ }^{1}$ Liaoning Academy of Agricultural Sciences, Shenyang, 110866, China.

Submitted Jul. 31, 2013; Revised Dec. 24, 2013; Accepted Mar. 4, 2014
}

Touchette et al., 2002). Because of the physiological and metabolic changes including transient fever, depressed feed intake and diversion of nutrients in support of immunerelated processes, immune challenge is considered an important economic loss case owing to growth inhibition and reduced efficiency of gain (Klasing and Johnstone, 1991; Spurlock, 1997). Many findings have converged to suggest that the foregoing physiological and metabolic changes induced by immunological challenge are mostly ascribed to the release of pro-inflammatory cytokines, including interleukin-1beta (IL-1 $\beta$ ), interleukin-6 (IL-6), and tumor necrosis factor (TNF)- $\alpha$ (Klasing et al., 1987; Klasing, 1988). Therefore, modulating the secretion of these

Copyright (? 2014 by Asian-Australasian Journal of Animal Sciences This is an open-access article distributed under the terms of the Creative Commons Attribution Non-Commercial License (http://creativecommons.org/licenses/by-nc/3.0/), which permits unrestricted non-commercial use, distribution, and reproduction in any medium, provided the original work is properly cited. 
cytokines by nutritional means of using natural substances with immunomodulatory traits offers methods of reducing the negative performance of immunologically challenged animals (Chen et al., 2003; Yin et al., 2008).

In China, Chinese herbal ingredients are natural substances which have been widely used to improve animal health (Yuan et al., 2006; Kong et al., 2007b; 2008; 2009b; Guo et al., 2008). Notably, recent studies demonstrating that extracts derived from Acanthopanax senticosus (AS), a well-known herb widely distributing in northern regions of Korea, Japan, and China (Deyama et al., 2001; Park et al., 2004), improved immune responses (Kong et al., 2007a), enhanced utilization efficiency of nutrition (Kong et al., 2009a), and modulated gut health of weaned piglets (Yin et al., 2008; Fang et al., 2009) have gained extensive attention. Above all, Acanthopanax senticosus polysaccharide (ASPS) as a extract typically concentrated in the root of AS, in human and rodents, has been shown to have potent immunomodulatory activity in vitro and in vivo by improving lymphocyte proliferation (Chen et al., 2011), inducing cytokine actions of interleukin-1beta (IL-1 $\beta$ ) and interleukin-6 (IL-6) (Steinmann et al., 2001), enhancing activities of B cells and phagocytosis of macrophages (Han et al., 2003), inhibiting the transferred tumor growths and ameliorating toxicities of toxic substances by immunomodulatory role of ASPS (Shen et al., 1991). Our previous research concerning the role of ASPS on improving performance and immune function in weaned piglets have been observed (Han et al., 2012a, b). However, within our knowledge, there is little information about the effects which ASPS exert its activities in weanling pigs under challenged condition. Therefore, the objective of current study was to determine the effects of ASPS supplementation on growth, immunity, blood parameters as well as the expression of pro-inflammatory cytokines genes in challenged piglets in order to probe into the effect on alleviation of depressed performance, especially on modulating immunological response and its underlying mechanism. We hypothesized that ASPS supplementation might bring some positive alternations in detrimental effect induced by an immunological challenge to piglets.

\section{MATERIALS AND METHODS}

All experiments were performed in accordance with the guidelines of Pig Production Association of Liaoning Province (China) and were approved by Animal Care Committee of Shenyang Agricultural University (China).

\section{Acanthopanax senticosus polysaccharide preparation and analysis}

Ethanol precipitation method according to Zhang et al.
(1993) was used to prepare ASPS with some modification. Briefly, crushed root was boiled to obtain filtrate, which was concentrated and protein removed by Sevag method (Staub, 1965). Subsequently, the solution was precipitated with ethanol to collect precipitate by centrifugation. The precipitate was dissolved in water and dialyzed for $24 \mathrm{~h}$ to remove the small molecular impurities, and then, the solution was concentrated again and purified by active carbon column chromatography with water and different concentration ethanol as eluent medium. Eluent was managed with reduced pressure, thus the tan powdery polysaccharide was obtained. Polysaccharide content was 92.74\% measured by the phenol sulfuric acid method (Dubois et al., 1956). Polysaccharide mainly consisted of glucose residues as determined by gas chromatography assay.

\section{Animals, management, designing}

Experiment (from June 5, 2012, to June 25, 2012) was conducted on the scientific pig farm of Shenyang Agriculture University (China). The formal feeding period lasted for $3 \mathrm{wks}$. The experiment was a $2 \times 2$ factorial arrangement including the main factors such as dietary ASPS supplementation ( 0 or $800 \mathrm{mg} / \mathrm{kg}$ ) (Han et al., 2012a) and immunological challenge (lipopolysaccharide [LPS] or saline injection). A total of 64 crossbred piglets (Duroc $\times$ Landrace $\times$ Large White), weaned at $28 \mathrm{~d}$ of age with average initial body weight (BW) of $7.25 \pm 0.21 \mathrm{~kg}$ were randomly assigned to 2 dietary groups with 8 replicate pens of 4 pigs per pen. On d 14, pigs in random four pens of per dietary treatment were intraperitoneally injected with $100 \mu \mathrm{g} / \mathrm{kg}$ BW LPS (Escherichia coli serotype 055:B5, Sigma) and the others were treated with equivalent amount of saline.

All pigs were housed in an environmentally controlled confinement house with concrete-slotted floor in 16 stainless steel pens $(2.0 \times 2.1 \mathrm{~m})$. Each pen was equipped with a self-feeder and a nipple drinker to allow the pigs $a d$ libitum access to feed and water. The temperature in the inner house ranged from $21.6^{\circ} \mathrm{C} \pm 2.3^{\circ} \mathrm{C}(6: 00$ to $7: 00$ am) to $23.2^{\circ} \mathrm{C} \pm 1.5^{\circ} \mathrm{C}(15: 00$ to $16: 00 \mathrm{pm})$ with $25.9^{\circ} \mathrm{C} \pm 2.1^{\circ} \mathrm{C}$ on average. The basal diet containing no antibiotic, presented in Table 1, was formulated according to the nutrient requirements of NRC (1998).

\section{Growth performance}

Surplus feed remaining in the feeder of each pen was cleared away and weighted daily to calculate average daily feed intake (ADFI). All piglets were weighed individually at the beginning of experiment to obtain the initial $\mathrm{BW}$, subsequently, BW was recorded again on d 14 and 21 to determine average daily gain (ADG), and gain:feed. 
Table 2. Effect of dietary ASPS supplementation on performance of weaned piglets challenged with LPS ${ }^{1}$

\begin{tabular}{|c|c|c|c|c|c|c|c|c|}
\hline \multirow[b]{2}{*}{ Items } & \multicolumn{2}{|c|}{- LPS } & \multicolumn{2}{|c|}{ +LPS } & \multirow[b]{2}{*}{ SEM } & \multicolumn{3}{|c|}{ p-value } \\
\hline & $\begin{array}{c}0 \mathrm{mg} \text { of } \\
\text { ASPS/kg }\end{array}$ & $\begin{array}{l}800 \mathrm{mg} \text { of } \\
\text { ASPS/kg }\end{array}$ & $\begin{array}{c}0 \mathrm{mg} \text { of } \\
\text { ASPS } / \mathrm{kg}\end{array}$ & $\begin{array}{l}800 \mathrm{mg} \text { of } \\
\mathrm{ASPS} / \mathrm{kg}\end{array}$ & & ASPS & LPS & Interaction \\
\hline \multicolumn{9}{|l|}{$\overline{\mathrm{ADG}(\mathrm{kg})}$} \\
\hline d 1 to 14 & 0.227 & 0.235 & 0.229 & 0.232 & 0.011 & 0.634 & 0.953 & 0.853 \\
\hline d 15 to 21 & $0.473^{\mathrm{a}}$ & $0.483^{\mathrm{a}}$ & $0.330^{\mathrm{b}}$ & $0.448^{\mathrm{a}}$ & 0.024 & 0.019 & 0.003 & 0.042 \\
\hline $\mathrm{d} 1$ to 21 & $0.309^{\mathrm{a}}$ & $0.318^{\mathrm{a}}$ & $0.262^{\mathrm{b}}$ & $0.304^{\mathrm{a}}$ & 0.008 & 0.007 & 0.002 & 0.054 \\
\hline \multicolumn{9}{|l|}{ ADFI (kg) } \\
\hline d 1 to 14 & 0.349 & 0.365 & 0.348 & 0.353 & 0.023 & 0.655 & 0.782 & 0.811 \\
\hline d 15 to 21 & $0.880^{\mathrm{a}}$ & $0.871^{\mathrm{a}}$ & $0.645^{\mathrm{b}}$ & $0.864^{\mathrm{a}}$ & 0.033 & 0.013 & 0.002 & 0.008 \\
\hline d 1 to 21 & 0.526 & 0.534 & 0.447 & 0.517 & 0.022 & 0.107 & 0.054 & 0.188 \\
\hline \multicolumn{9}{|l|}{ Gain:feed } \\
\hline d 1 to 14 & 0.652 & 0.647 & 0.657 & 0.687 & 0.025 & 0.814 & 0.692 & 0.758 \\
\hline d 15 to 21 & 0.538 & 0.556 & 0.520 & 0.521 & 0.029 & 0.824 & 0.534 & 0.850 \\
\hline d 1 to 21 & 0.588 & 0.596 & 0.588 & 0.602 & 0.071 & 0.767 & 0.949 & 0.934 \\
\hline
\end{tabular}

ASPS, Acanthopanax senticosus polysaccharide; LPS, lipopolysaccharide; SEM, standard error of the mean; ADG, average daily gain; ADFI, average daily feed intake.

${ }^{1}$ Values were represented as means of four pens with four pigs per pen

${ }^{\mathrm{a}, \mathrm{b}}$ Different superscript in a row indicates significant difference at $\mathrm{p}<0.05$.

were observed, $28 \mathrm{~s} / 18 \mathrm{~s}$ ratio in width and brightness was more than 1.5 based on the analysis of biological software.

First-strand cDNA was synthesized in a reverse transcription reaction system of $20 \mu \mathrm{L}$ containing 0.05 $\mu \mathrm{g} / \mu \mathrm{L}$ of purified total RNA, $0.5 \mathrm{mmol} / \mathrm{L}$ oligo $\mathrm{dT}, 2$ $\mathrm{mmol} / \mathrm{L} 5 \times \mathrm{RT}$ buffer, $0.5 \mathrm{mmol} / \mathrm{L} \mathrm{dNTP}, 1 \mathrm{U} / \mu \mathrm{L}$ RNasin and $10 \mathrm{U} / \mu \mathrm{L}$ reverse transcriptase (MMLV, Toyobo, Osaka, Japan). The synthesized first-strand cDNA samples were diluted by ultra-purified water. Gene expression at mRNA level was analyzed by quantitative real-time polymerase chain reaction (PCR) with specific primers designed by Premier 5.0 software. Gene-specific primers for $\beta$-actin (forward: 5'-TGCGGGACATCAAGGAGAAG-3'; reverse: 5'-AGTTG AAGGTAGTTTCGTGG-3'; GenBank sequence No: XM-00312428.1), IL-1 $\beta$ (forward: 5'TGGCAGTCCTCTG TCCTTG-3'; reverse: 5'GATCTTTCACAGACACTGCT GC-3'; GenBank sequence No: GI:47522925), IL-6 (forward: 5'AGTCCAGTCGCCTTCTCCCT-3'; reverse: 5'CAGAGATTTTGCCGAGGATG-3'; GenBank sequence No: GI:47523851) and TNF- $\alpha$ (forward: 5'-CCACGCTC TTCTGCCTACTG-3'; reverse: 5'-GCTGATGGTGTGAGT GAGGAA-3'; GenBank sequence No: GI:189176152) were synthesized by Dingguo Changsheng Biotech Co. (Beijing, China). PCR was performed in a $20 \mu \mathrm{L}$ reaction system containing $10 \mu \mathrm{L} 2 \times$ Taq RCR Master Mix (Genview, Tempe, AZ, USA), $2 \mu \mathrm{L}$ cDNA template, $0.5 \mu \mathrm{mol} / \mathrm{L}$ uppremier and down-premier respectively. The real-time PCR cycling conditions were a pre-denaturation cycle at $94^{\circ} \mathrm{C}$ for 5 min firstly, followed by 35 cycles at $95^{\circ} \mathrm{C}$ for $30 \mathrm{~s}$, $51^{\circ} \mathrm{C} / 55^{\circ} \mathrm{C} / 58^{\circ} \mathrm{C} / 56^{\circ} \mathrm{C}$ for $30 \mathrm{~s}$, then 1 cycle at $72^{\circ} \mathrm{C}$ for 10 min. Amplification and melt-curve analysis were performed in Mx3005P (Agilent Stratagene, Los Angeles, CA, USA).
The relative concentration of mRNA was evaluated by the $2^{-\Delta \Delta C t}$ method (Livak and Schmittgen, 2001).

\section{Statistical analysis}

The pen was used as the experimental unit for the analysis of growth performance, whereas individual piglet was used as experimental unit for analysis of blood parameters and spleen pro-inflammatory cytokines. The data for all parameters were recorded for each experimental unit and statistically analyzed by one-way analysis of variance and univariate analysis using (general llinear model) procedures of SPSS 16.0 software (INC SPSS, 2008) basing on the main factors including ASPS treatment and LPS challenge. Difference significance was taken at $\mathrm{p}<0.05$, and there was tendency toward statistical significance if $\mathrm{p}<0.10$.

\section{RESULTS}

\section{Effect of Acanthopanax senticosus polysaccharide on growth performance}

As given in Table 2, prior to LPS challenge (from d 1 to 14), ASPS did not affect performance ( $\mathrm{p}>0.05)$. Following LPS challenge (from d 15 to 21), suppressed ADG and ADFI were observed by LPS challenge $(\mathrm{p}<0.05)$. Correspondingly, pigs fed ASPS have a $15.94 \%$ higher ADG $(p<0.05)$ and a $13.77 \%$ higher ADFI than those fed non-supplemented control regardless of the challenge, and interaction between LPS $\times$ ASPS was also observed on ADG and ADFI $(p<0.05)$. Through 21-d trial, there was a tendentious interaction on ADG $(\mathrm{p}<0.1)$. In addition, for LPS-challenged pigs fed ASPS had a $35.76 \%$ higher ADG and a $33.95 \%$ higher ADFI than the non-additive group 
Table 3. Effect of dietary ASPS supplementation on peripheral immune parameters of weaned piglets challenged with LPS ${ }^{1}$

\begin{tabular}{|c|c|c|c|c|c|c|c|c|}
\hline \multirow[b]{2}{*}{ Items } & \multicolumn{2}{|c|}{-LPS } & \multicolumn{2}{|c|}{$+\mathrm{LPS}$} & \multirow[b]{2}{*}{ SEM } & \multicolumn{3}{|c|}{ p-value } \\
\hline & $\begin{array}{c}0 \mathrm{mg} \text { of } \\
\text { ASPS } / \mathrm{kg}\end{array}$ & $\begin{array}{l}800 \mathrm{mg} \text { of } \\
\text { ASPS/kg }\end{array}$ & $\begin{array}{c}0 \mathrm{mg} \text { of } \\
\text { ASPS/kg }\end{array}$ & $\begin{array}{l}800 \mathrm{mg} \text { of } \\
\mathrm{ASPS} / \mathrm{kg}\end{array}$ & & ASPS & LPS & Interaction \\
\hline $\operatorname{IgG}(\mathrm{g} / \mathrm{L})$ & 8.74 & 7.92 & 8.28 & 8.66 & 0.26 & 0.80 & 0.69 & 0.29 \\
\hline Lymphocyte proliferation $^{2}$ & $1.63^{\mathrm{a}}$ & $1.72^{\mathrm{b}}$ & $1.75^{\mathrm{b}}$ & $1.78^{\mathrm{c}}$ & 0.02 & 0.02 & $<0.01$ & 0.04 \\
\hline Lymphocyte to leucocyte ratio (\%) & 48.58 & 50.22 & 54.05 & 70.14 & 3.87 & 0.24 & 0.10 & 0.33 \\
\hline Leucocyte number $\left(10^{9} / \mathrm{L}\right)$ & $21.88^{\mathrm{a}}$ & $17.58^{\mathrm{a}}$ & $24.93^{\mathrm{ab}}$ & $31.68^{\mathrm{b}}$ & 2.58 & 0.05 & $<0.01$ & 0.63 \\
\hline
\end{tabular}

ASPS, Acanthopanax senticosus polysaccharide; LPS, lipopolysaccharide; SEM, standard error of the mean.

${ }^{1}$ Values represent the means of four pens with one pig per pen.

${ }^{2}$ Values are expressed as stimulation index calculated as the ratios of absorbance of wells incubated with Con A to absorbance of wells incubated without Con A.

${ }_{\text {a,b,c }}$ Different superscript in a row indicates significant difference at $\mathrm{p}<0.05$.

$(\mathrm{p}<0.05)$, however, ADG and ADFI were insignificant improved by dietary ASPS among saline-injected pigs.

\section{Effect of Acanthopanax senticosus polysaccharide on immunological responses}

As indicated in Table 3, LPS challenge improved lymphocyte proliferation $(\mathrm{p}<0.05)$, lymphocyte to leucocyte ratio $(\mathrm{p}<0.1)$, and leucocyte number $(\mathrm{p}<0.05)$. Dietary ASPS significantly promoted lymphocyte proliferation $(p<0.05)$ and leucocyte number $(p<0.1)$ compared with the non-additive group and ignoring LPS challenge. There was no LPS $\times$ ASPS interaction revealed on these indices except lymphocyte proliferation $(\mathrm{p}<0.05)$. However, circulatory concentration of IgG was influenced $(p>0.05)$ neither by ASPS, LPS nor their interaction. ASPS supplementation improved lymphocyte proliferation among saline-injected and LPS-injected pigs.

The plasma cytokines concentration and spleen expression of proinflammatory cytokines mRNA

As presented in Table 4, the plasma concentration of IL$1 \beta$, IL- 6 , and TNF- $\alpha$ were induced to increase $(\mathrm{p}<0.05)$ by LPS challenge. In contrast, these indices were decreased by dietary ASPS ( $\mathrm{p}<0.05)$, and an interaction between ASPS $\times$
LPS was found on these cytokines. Dietary ASPS also resulted in down-regulation $(\mathrm{p}<0.05)$ of IL-1 $\beta$, IL-6, and TNF- $\alpha$ mRNA expression in spleen, and ASPS $\times$ LPS interaction were detected on mRNA expression of IL-1 $\beta$ as well as IL-6 ( $p<0.05)$. In addition, for LPS-challenged pigs, dietary ASPS significantly reduced the circulating concentration and mRNA expression of IL-1 $\beta$, IL- 6 as well as TNF- $\alpha(\mathrm{p}<0.05)$ compared with non-supplemented group. Whereas, ASPS had no effect on these indices among saline-injected pigs.

\section{Plasma hormones and biochemical parameters analysis}

As showed in Table 5, decreased plasma concentration of GH and IGF-I were revealed $(\mathrm{p}<0.05)$ in pigs suffering from LPS challenge. Correspondingly, GH and IGF-I concentrations were increased $(p<0.05)$ in pigs fed ASPS regardless of LPS challenge. ASPS additive also significantly lowered $(\mathrm{p}<0.05)$ the concentration of $\alpha$-AGP, BUN, NEFA, and glucose. Moreover, interaction effects were observed on above indices $(\mathrm{p}<0.05)$ except GH $(\mathrm{p}>0.05)$ and BUN $(\mathrm{p}<0.1)$. For the LPS-injected pigs, dietary ASPS lowered plasma GH, IGF-I, $\alpha$-AGP, NEFA, and glucose $(\mathrm{p}<0.05)$ than non-additive group.

Table 4. Effects of dietary ASPS supplementation on plasma concentration of pro-inflammatory cytokines and its relative mRNA level in spleen of weaned piglets challenged with LPS $^{1}$

\begin{tabular}{|c|c|c|c|c|c|c|c|c|}
\hline \multirow[b]{2}{*}{ Items } & \multicolumn{2}{|c|}{$-\mathrm{LPS}$} & \multicolumn{2}{|c|}{$+\mathrm{LPS}$} & \multirow[b]{2}{*}{ SEM } & \multicolumn{3}{|c|}{ p-value } \\
\hline & $\begin{array}{c}0 \mathrm{mg} \text { of } \\
\text { ASPS } / \mathrm{kg}\end{array}$ & $\begin{array}{l}800 \mathrm{mg} \text { of } \\
\text { ASPS/kg }\end{array}$ & $\begin{array}{c}0 \mathrm{mg} \text { of } \\
\text { ASPS/kg }\end{array}$ & $\begin{array}{c}800 \mathrm{mg} \text { of } \\
\text { ASPS } / \mathrm{kg}\end{array}$ & & ASPS & LPS & Interaction \\
\hline$\overline{\mathrm{IL}}-1 \beta$ (ng/L) & $264.06^{\mathrm{a}}$ & $265.72^{\mathrm{a}}$ & $337.86^{\mathrm{b}}$ & $270.44^{\mathrm{a}}$ & 12.50 & 0.02 & $<0.01$ & 0.02 \\
\hline IL-6 (ng/L) & $39.71^{\mathrm{a}}$ & $40.21^{\mathrm{a}}$ & $56.50^{\mathrm{b}}$ & $40.02^{\mathrm{a}}$ & 2.93 & 0.02 & 0.02 & 0.01 \\
\hline TNF- $\alpha(n g / L)$ & $284.92^{\mathrm{a}}$ & $292.62^{\mathrm{a}}$ & $366.20^{\mathrm{b}}$ & $279.73^{\mathrm{a}}$ & 15.05 & 0.02 & 0.04 & $<0.01$ \\
\hline IL-1 $\beta$ mRNA & $0.12^{\mathrm{a}}$ & $0.01^{\mathrm{a}}$ & $26.61^{\mathrm{c}}$ & $8.38^{\mathrm{b}}$ & 3.37 & $<0.01$ & $<0.01$ & 0.04 \\
\hline IL-6 mRNA & $0.11^{\mathrm{a}}$ & $0.09^{\mathrm{a}}$ & $5.58^{\mathrm{b}}$ & $0.15^{\mathrm{a}}$ & 0.71 & $<0.01$ & $<0.01$ & $<0.01$ \\
\hline TNF- $\alpha$ mRNA & $0.80^{\mathrm{a}}$ & $0.66^{\mathrm{a}}$ & $3.81^{\mathrm{c}}$ & $2.83^{\mathrm{b}}$ & 0.42 & 0.04 & $<0.01$ & 0.10 \\
\hline
\end{tabular}

ASPS, Acanthopanax senticosus polysaccharide; LPS, lipopolysaccharide; SEM, standard error of the mean; IL-1 $\beta$, interleukin-1beta; IL-6, interleukin-6;

TNF- $\alpha$, tumor necrosis factor-alpha.

${ }^{1}$ Values represent the means of four pens with one pig per pen.

${ }^{\mathrm{a}, \mathrm{b}, \mathrm{c}}$ Different superscript in a row indicates significant difference at $\mathrm{p}<0.05$. 
Table 5. Effect of dietary ASPS supplementation on some plasma parameters of weaned piglets challenged with LPS ${ }^{1}$

\begin{tabular}{|c|c|c|c|c|c|c|c|c|}
\hline \multirow[b]{2}{*}{ Items } & \multicolumn{2}{|c|}{-LPS } & \multicolumn{2}{|c|}{+ LPS } & \multirow[b]{2}{*}{ SEM } & \multicolumn{3}{|c|}{$\mathrm{p}$-value } \\
\hline & $\begin{array}{c}0 \mathrm{mg} \text { of } \\
\text { ASPS/kg }\end{array}$ & $\begin{array}{l}800 \mathrm{mg} \text { of } \\
\text { ASPS/kg }\end{array}$ & $\begin{array}{c}0 \mathrm{mg} \text { of } \\
\text { ASPS } / \mathrm{kg}\end{array}$ & $\begin{array}{l}800 \mathrm{mg} \text { of } \\
\mathrm{ASPS} / \mathrm{kg}\end{array}$ & & ASPS & LPS & Interaction \\
\hline$\overline{\mathrm{GH}}(\mu \mathrm{g} / \mathrm{L})$ & $17.12^{\mathrm{a}}$ & $17.501^{\mathrm{a}}$ & $15.47^{\mathrm{b}}$ & $17.17^{\mathrm{a}}$ & 0.46 & 0.04 & 0.049 & 0.17 \\
\hline IGF- I $(\mu \mathrm{g} / \mathrm{L})$ & $122.18^{\mathrm{a}}$ & $124.02^{\mathrm{a}}$ & $110.31^{\mathrm{b}}$ & $123.53^{\mathrm{a}}$ & 2.60 & 0.01 & 0.035 & 0.049 \\
\hline$\alpha-\mathrm{AGP}^{3}(\mathrm{ng} / \mathrm{L})$ & $147.38^{\mathrm{a}}$ & $131.68^{\mathrm{a}}$ & $186.61^{\mathrm{b}}$ & $136.75^{\mathrm{a}}$ & 6.58 & $<0.01$ & $<0.01$ & 0.03 \\
\hline BUN (mmol/L) & $14.07^{\mathrm{ab}}$ & $8.60^{\mathrm{a}}$ & $18.83^{\mathrm{b}}$ & $14.59^{\mathrm{ab}}$ & 1.32 & 0.03 & 0.049 & 0.09 \\
\hline $\mathrm{NEFA}(\mu \mathrm{mol} / \mathrm{L})$ & $62.64^{\mathrm{a}}$ & $51.17^{\mathrm{a}}$ & $322.60^{c}$ & $265.22^{\mathrm{b}}$ & 42.68 & 0.02 & 0.02 & 0.02 \\
\hline Glucose (mmol/L) & $2.23^{\mathrm{a}}$ & $1.57^{\mathrm{b}}$ & $2.29^{\mathrm{a}}$ & $1.82^{\mathrm{c}}$ & 0.27 & 0.04 & 0.01 & 0.03 \\
\hline
\end{tabular}

ASPS, Acanthopanax senticosus polysaccharide; LPS, lipopolysaccharide; SEM, standard error of the mean; GH, growth hormone; IGF-I, insulin-like growth factor-I; $\alpha$-AGP, $\alpha$-acid glycoprotein; BUN, blood urea nitrogen; NEFA, nonesterified fatty acid.

${ }^{1}$ Values represent the means of four pens with one pig per pen.

${ }^{a, b, c}$ Different superscript in a row indicates significant difference at $\mathrm{p}<0.05$.

\section{DISCUSSION}

In the current study, the well-documented piglets infected model built by injecting LPS (Johnson and Von Borell, 1994; Lai et al., 2005), which is a molecule present on the membrane of gram-negative bacteria, was used to evaluate the effect of dietary ASPS on immunological challenge. Our finding that LPS challenge reduced their performance is consistent with previous research in pigs (Guo et al., 2008) and indicates the suitability of the challenge model in our study.

In recent years, there has been increasing interest in using polysaccharides to improve growth performance in young animals (Kong et al., 2009b; Li et al., 2009). However, to our knowledge, little research was conducted to determine the effect that ASPS exerted on growth performance in weanling pigs. In the present study, the results of dietary ASPS improving the growing rate of piglets were similar to $\mathrm{Wu}$ et al. (2010) who found that growth performance of weaned pigs were increased by the addition of AS extracts (ASE), which contains compound active ingredients besides polysaccharide. Furthermore, ASPS supplementation insignificantly affected performance before LPS challenge. Coactions between ASPS and LPS were observed on ADG and ADFI following LPS challenge suggesting that dietary ASPS can alleviate the detrimental performance induced by LPS immunological stress. At the same time, it also clearly indicated a more important effect of dietary ASPS under stress than under normal conditions.

In the current study, the blood cell number, lymphocyte proliferation and antibody were measured to determine the role of ASPS on ability to resist pathogens and the immune response during immunological challenge. Leukocytes and lymphocyte serving as important components of the innate immune system can recognize non-specifically different pathogens and can predict underlying infection (Medzhitov and Janeway, 2000) or stress (McGlone et al., 1983). Therefore, in the present study, an increase in circulating leukocytes number and lymphocyte to leukocyte ratio after challenge accords with the research by McGlone et al. (1983) to imply an underlying bacterial infection or stress in piglets. However, ASPS supplementation tendentious increased of leukocyte number suggesting a latent role of ASPS in enhancing resistance to disease.

Lymphocyte proliferation stimulated by Con A can be indicative of cellular immunity. Our study concerning the markedly improved lymphocyte proliferation activity indicates an activated immune system by LPS challenge. At same time, ASPS supplementation improved lymphocyte proliferation among LPS-injected and saline-injected pigs, which was in agreement with previous study by Chen et al. (2011) suggesting that lymphocyte proliferative responses of mice spleen induced by Con A was enhanced by ASPS in vitro. Kong et al. (2007) demonstrated that ASE can enhance cellular responses of weaned piglets, highlight the enhanced immunostimulating effect of ASPS on cellular immunity, which was also similar to the research by Kong et al. (2009b) who reported that Chinese yam polysaccharide enhanced cellular immune response in weanling rats. The plasma IgG serves as an important criterion of humoral immunity which has the effect of strengthening phagocytosis of bacteria by the immune cell. Our finding of an insignificant effect on IgG by dietary ASPS might suggest its inefficacy in improving humoral immunity. As a matter of fact, a dissimilar result by Kong et al. (2007) suggested that serum IgG concentration in pigs was enhanced by ASE. Han et al. (2003) also demonstrated ASPS selectively activated $B$ cells rather than $T$ cells in mice. The contradictory results between our study and previous reports may be associated with the species of experimental animal and the method of extracting herbal ingredients. Collectively, these results suggest that dietary ASPS maybe improve cellular immunity, and the underlying mechanism for improving lymphocyte proliferation by ASPS needs further research.

The release of pro-inflammatory cytokines to activate immune system during the period of immunological stress is critical for improving immune response and resistance 
(Johnson, 1997). However, excessive secretion of these cytokines can reduce feed intake, direct nutrients in support of immune function and ultimately reduces growth (Spurlock, 1997). In our study, the sharply elevated circulating concentration of IL-1 $\beta$, IL-6, and TNF- $\alpha$, especially spleen mRNA expression of these cytokines following LPS challenge indicate the immune response was speedy and excessive activated, which is agreement with Guo et al. (2008) and Lai et al. (2005). For the pigs given LPS, the findings concerning diet with ASPS lowering circulating concentrations and mRNA expression of spleen pro-inflammatory cytokines suggest that ASPS supplementation contributes to a less activated immune system and more nutrients directed to support growth. These results propose that decrease in excessive activation of the immune system may be the mechanism by which growth and feed intake are improved when ASPS is included in post-weaning diet. This may partially explain the reason of higher performance obtained in LPSadministrated pigs fed ASPS.

As the important component of somatotropic axis, GH is a key anabolic hormone and its anabolic action is accomplished in part by the induction of IGF-I (Hevener et al., 1997). In the present study, reducted concentration of circulatory GH and IGF-I was revealed in pigs given LPS administration, and is in accordance with the previous reports by Elsasser et al. (1988) and Guo et al. (2008). Previous research also suggested that the decrease in IGF-I was the important indicator of repartitioning of nutrients away from growth to immune function during immunological challenge (Soto et al., 1998; Wright et al., 2000). Therefore, the observed interaction between LPS and ASPS on IGF-I indicates the mitigated decrease in IGF-I owning to ASPS supplementation may be associated with alleviating the abnormal changes of somatotropic axis and improving growth performance among LPS challenged pigs fed ASPS.

Previous research by Klasing (1988) and Johnson (1997) proposed that pro-inflammatory cytokines released during immunological challenge are major mediators of intermediary metabolism. These cytokines reduced glucose uptake by the organisms tissues (Lang et al., 1992; Ling et al., 1994), increased plasma NEFA derived from adipose tissue (Memon et al., 1994), elevated circulatory BUN (Webel et al., 1997; Le Floc'h et al., 2004) and accelerated muscle protein degradation in synthesis of $\alpha$-AGP in liver (Richards et al., 1991), which are an important hallmarks of an immunological response (Johnson, 1997). Above previous reports rationally interprets why increased circulatory $\alpha$-AGP, BUN, NEFA as well as glucose occurred in the current study after LPS administration. Correspondingly, the results of LPS-administrated pigs fed with ASPS showing a significant attenuated the reduction of $\alpha$-AGP, NEFA, and glucose compared with those fed with non-additive confirmed the enhanced anabolism of challenged animals and suggests that dietary ASPS involved in regulating growth inhibition might be closely related to the suppression of the release of pro-inflammatory cytokines.

\section{CONCLUSION}

The present study demonstrates that ASPS additive to the diet of piglets could mitigate the excessive immunological response to LPS challenge by modulating the release of pro-inflammatory cytokines, which enable pigs to achieve better growth performance. These results suggest that lowering excessive activation of immune system may be the mechanism by which growth rate and feed intake are improved when ASPS is used as natural derived immunomodulating agent of weaned pigs.

\section{ACKNOWLEDGMENTS}

The work was supported by National "Twelfth FiveYear" Plan for Science and Technology Support Program (2011BAD28B01-02).

\section{REFERENCES}

Blecha, F. and B. Charley. 1990. Rationale for using immunpotentiators in domestic food animals. In Immunomodulation in Domestic Food Animals (Ed. F. Blecha and B. Charley). Academic Press, San Diego, CA. pp. 3-19.

Chen, H. L., D. F. Li, B. Y. Chang, L. M. Gong, J. G. Dai, and G. F. Yi. 2003. Effects of Chinese herbal polysaccharides on the immunity and growth performance of young broilers. Poult. Sci. 82:364-370.

Chen, R. Z., Z. Q. Liu, J. M. Zhao, R. P. Chen, F. L. Meng, M. Zhang, and W. C. Ge. 2011. Antioxidant and immunobiological activity of water-soluble polysaccharide fractions purified from Acanthopanax senticosus. Food Chem. 127:434-440

Deyama, T., S. Nishibe, and Y. Nakazawa. 2001. Constituents and pharmacological effects of Eucommia and Siberian ginseng. Acta. Pharmacol. Sin. 22:1057-1070.

DuBois, M., K. A. Gilles, J. K. Hamilton, P. A. Rebers, and F. Smith. 1956. Colorimetric method for determination of sugars and related substances. Anal. Chem. 28:350-356.

Elsasser, T. H., T. S. Rumsey, A. C. Hammond, and R. Fayer. 1988. Influence of parasitism on plasma concentrations of growth hormone, somatomedin- $\mathrm{C}$, and somatomedin binding proteins in calves. J. Endocrinol. 116:191-200.

Fan, J., M. M. Wojnar, M. Theodorakis, and C. H. Lang. 1996. Regulation of insulin-like growth factor (IGF)-I mRNA and peptide and IGF-binding proteins by interleukin-1. Am. J. Physiol. 270:R621-R629. 
Fang, J., F. Y. Yan, X. F. Kong, Z. Ruan, Z. Q. Liu, R. L. Huang, T. J. Li, M. M. Geng, F. Yang, Y. Z. Zhang, P. Li, Joshua Gong, G. Y. Wu, M. Z. Fan, Y. L. Liu, Y. Q. Hou, and Y. L. Yin. 2009. Dietary supplementation with Acanthopanax senticosus extract enhances gut health in weanling piglets. Livest. Sci. 123:268275 .

Guo, G. L., Y. L. Liu, W. Fan, J. Han, Y. Q. Hou, Y. L. Yin, H. L. Zhu, B. Y. Ding, J. X. Shi, J. L. Lu, H. R. Wang, J. Chao, and Y. H. Qu. 2008. Effects of Achyranthes Bidentata polysaccharide on growth performance, immunological, adrenal, and somatotropic responses of weaned pigs challenged with Escherichia coli lipopolysaccharide. Asian Australas. J. Anim. Sci. 21:1189-1195.

Han, J., L. Q. Bian, X. J. Liu, F. Zhang, and K. K. Yang. 2012a. Effects of dietary Acanthopanax senticosus polysaccharide on growth performance and immune parameters of weaner piglets. Chin. J. Anim. Nutr. 24: 2203-2209.

Han, J., L. Q. Bian, X. J. Liu, F. Zhang, and K. K. Yang. 2012b. Effects of dietary Acanthopanax senticosus polysaccharide on immune parameters in blood of weaner piglets. Chin. J. Anim. Nutr. 24:2444-2449.

Han, S. B., Y. D. Yoon, H. J. Ahn, H. S. Lee, C. W. Lee, W. K. Yoon, S. K. Park, and H. M. Kim. 2003. Toll-like receptormediated activation of $\mathrm{B}$ cells and macrophages by polysaccharide isolated from cell culture of Acanthopanax senticosus. Int. lmmunopharmacol. 3:1301-1312.

Hevener, W., G. W. Almond, J. D. Armstrong, and R. G. Richards. 1997. Effects of acute endotoxemia on serum somatotropin and insulin-like growth factor I concentrations in prepubertal gilts. Am. J. Vet. Res. 58:1010-1013.

Johnson, R. W. and E. Von Borell. 1994. Lipopolysaccharideinduced sickness behavior in pigs is inhibited by pretreatment with indomethacin. J. Anim. Sci. 72:309-314.

Johnson, R. W. 1997. Inhibition of growth by pro-inflammatory cytokines: an integrated view. J. Anim. Sci. 75:1244-1255.

Kelley, K. W., R. W. Johnson, and R. Dantzer. 1994. Immunology discovers physiology. Vet. Immunol. Immunopathol. 43:157165.

Klasing, K. C. and B. J. Johnstone. 1991. Monokines in growth and development. Poult. Sci. 70:1781-1789.

Klasing, K. C. 1988. Nutritional aspects of leukocytic cytokines. J. Nutr. 118:1436-1446.

Klasing, K. C., D. E. Laurin, R. K. Peng, and D. M. Fry. 1987. Immunologically mediated growth depression in chicks: Influence of feed intake, corticosterone and interleukin-1. J. Nutr. 117:1629-1637.

Kong, X. F., Y. L.Yin, G. Y. Wu, H. J. Liu, F. G. Yin, T. J. Li, R. L. Huang, Z. Ruan, H. Xiong, Z. Y. Deng, M. Y. Xie, Y. P. Liao, and S. W. Kim. 2007a. Dietary supplementation with Acanthopanax senticosus extract modulates cellular and humoral immunity in weaned piglets. Asian Australas. J. Anim. Sci. 20:1453-1461.

Kong, X. F., Y. L. Yin, Q. H. He, F. G. Yin, H. J. Liu, T. J. Li, R. L. Huang, M. M. Geng, Z. Ruan, Z. Y. Deng, M. Y. Xie, and G. Wu. 2008. Dietary supplementation with Chinese herbal powder enhances ileal digestibilities and serum concentrations of amino acids in young pigs. Amino Acids. 37:573-582.

Kong, X. F., G. Y. Wu, Y. P. Liao, Z. P. Hou, H. J. Liu, F. G. Yin, T.
J. Li, R. L. Huang, Y. M. Zhang, D. Deng, P. Kang, R. X. Wang, Z. Y. Tang, C. B. Yang, Z. Y. Deng, H. Xiong, W. Y. Chu, Z. Ruan, M. Y. Xie, and Y. L. Yin. 2007b. Effects of Chinese herbal ultra-fine powder as a dietary additive on growth performance, serum metabolites and intestinal health in early-weaned piglets. Livest. Sci. 108:272-275.

Kong, X. F., F. G. Yin, Q. H. He, H. J. Liu, T. J. Li, R. L. Huang, M. Z. Fan, Y. L. Liu, Y. Q. Hou, P. Li, Z. Ruan, Z. Y. Deng, M. Y. Xie, H. Xiong, and Y. L. Yin. 2009a. Acanthopanax senticosus extract as a dietary additive enhances the apparent ileal digestibility of amino acids in weaned piglets. Livest. Sci. 123:261-267.

Kong, X. F., Y. Z. Zhang, Y. L. Yin, G. Y. Wu, H. J. Zhou, Z. L. Tan, F. Yang, M. J. Bo, R. L. Huang, T. J. Li, and M. M. Geng. 2009b. Chinese Yam polysaccharide enhances growth performance and cellular immune response in weanling rats. J. Sci. Food Agric. 89:2039-2044.

Lai, C. H., J. D. Yin, D. F. Li, L. D. Zhao, S. Y. Qiao, and J. J. Xing. 2005. Conjugated linoleic acid attenuates the production and gene expression of proinflammatory cytokines in weaned pigs challenged with lipopolysaccharide. J. Nutr. 135:239-244.

Lang, C. H., C. Dobrescu, and G. J. Bagby. 1992. Tumor necrosis factor impairs insulin action on peripheral glucose disposal and hepatic glucose output. Endocrinology 130:43-52.

Le Floc'h, N. L., D. Melchior, and C. Obled. 2004. Modifications of protein and amino acid metabolism during inflammation and immune system activation. Livest. Prod. Sci. 87:37-45.

Li, L. L., X. Wu, H. Z. Peng, M. Z. Fan, Z. P. Hou, X. F. Kong, Y. L. Yin, B. Zhang, T. J. Li, Y. Q. Hou, K. M .Yang, A. K. Li, C. Y. Liu, X. M. Qiu, and Y. L. Liu. 2009. The effect of dietary addition of a polysaccharide from Atractylodes macrophala Koidz on growth performance, immunoglobulin concentration and IL-1 $\beta$ expression in weaned piglets. J. Agric. Sci. 147: 625-631.

Ling, P. R., B. R. Bistrian, B. Mendez, and N. W. Istfan. 1994. Effects of systemic infusions of endotoxin, tumor necrosis factor, and interleukin-1 on glucose metabolism in the rat: Relationship to endogenous glucose production and peripheral tissue glucose uptake. Metabolism 43:279-284.

Livak, K. J. and T. D. Schmittgen. 2001. Analysis of relative gene expression data using real-time quantitative PCR and the $2^{-\Delta \Delta C t}$ method. Methods 25:402-408.

McGlone, J. J., J. L. Salak, E. A. Lumpkin, R. I. Nicholson, M. Gibson, and R. L. Norman. 1983. Shipping stress and social status effects on pig performance, plasma cortisol, natural killer cell activity, and leukocyte numbers. J. Anim. Sci. 71: 888-896.

Memon, R. A., K. R. Feingold, and C. Grunfeld. 1994. The effects of cytokines on intermediary metabolism. Endocrinologist 4 : 59-63.

Medzhitov, R. and C. Janeway. 2000. Innate immune recognition:mechanisms and pathways. Immunol. Rev. 173: 89-97.

Mosmann, T. 1983. Rapid colorimetric assay for cellular growth and survival: application to proliferation and cytotoxicity assays. J. Immunol. Method 65:55-63.

NRC. 1998. Nutrient Requirements of Swine. 10th ed. National Academy Press, Washington, DC. 
Park, E. J., J. X. Nan, Y. Z. Zhao, S. H. Lee, Y. H. Kim, J. B. Nam, J. J. Lee, and D. H. Sohn. 2004. Water-soluble polysaccharide from Eleutherococcus senticosus stems attenuates fulminant hepatic failure induced by D-galactosamine and lipopolysaccharide in mice. Basic Clin. Pharmacol. Toxicol. 94:298-304.

Richards, C., J. Gauldie, and H. Baumann. 1991. Cytokine control of acute phase protein expression. Eur. Cytokine Netw. 2 89-98.

Shen, M. L., S. K. Zhai, H. L. Chen, Y. D. Luo, G. R. Tu, and D. W. Ou. 1991. Immunomopharmacological effects of polysaccharides from Acanthopanax senticosus on experimental animals. Int. J. Immunopharmacol. 13:549-554.

Soto, L., A. I. Martin, S. Millán, E. Vara, and A. López-Calderón. 1998. Effects of endotoxin lipopolysaccharide administration on the somatotropic axis. J. Endocrinol. 159:239-246.

Spurlock, M. E. 1997. Regulation of metabolism and growth during immune challenge: An overview of cytokine function. J. Anim. Sci. 75:1773-1783.

Steinmann, G. G., A. Esperester, and P. Joller. 2001 Immunopharmacological in vitro effects of Eleutheroeoceus senticosus extracts. Arzneimittelforschung 51:76-83.

Staub, A. M. 1965. Removal of protein-sevag method. In: Methods in Carbohydrate Chemistry (ED. R. L. Whistler). Academic Press, New York, USA.

Touchette, K. J., J. A. Carroll, G. L. Allee, R. L. Matteri, C. J. Dyer, L. A. Beausang and M. E. Zannelli. 2002. Effect of spray-dried plasma and lipopolysaccharide exposure on weaned pigs: I. Effects on the immune axis of weaned pigs. J. Anim. Sci. 80: 494-501.
Wagner, H., A. Proksch, I. Riess-Maurer, A. Vollmar, S. Odenthal, H. Stuppner, K. Jurcic, T. M. Le, and J. N. Fang. 1985. Immunostimulating action of polysaccharides (heteroglycans) from higher plants. Arzneimittelforschung 35:1069-1075.

Webel, D. M., B. N. Finck, D. H. Baker, and R. W. Johnson. 1997. Time course of increased plasma cytokines, cortisol, and urea nitrogen in pigs following intraperitoneal injection of lipopolysaccharide. J. Anim. Sci. 75:1514-1520

Wright, K. J., R. Balaji, C. M. Hill, S. S. Dritz, E. L. Knoppel, and J. E. Minton. 2000. Integrated adrenal, somatotropic, and immune responses of growing pigs to treatment with lipopolysaccharide. J. Anim. Sci. 78:1892-1899.

Wu, X., F. Y. Yan, X. F. Kong, T. J. Li, R. L. Huang, L. X. Chen, and Y. L. Yin. 2010. Effects of Acanthopanax senticosus extract on growth performance and anti-oxidative capacity in weaned piglet. Nat. Prod. Res. Dev. 22:297-301.

Yin, F. G., Y. L. Yin, X. F. Kong, Y. L. Liu, Q. H. He, T. J. Li, R. L. Huang, Y. Q. Hou, X. G. Shu, L. X. Tan, L. X. Chen, J. H. Gong, S. W. Kim, and G. Y. Wu. 2008. Dietary supplementation with Acanthopanax senticosus extract modulates gut microflora in weaned piglets. Asian Australas. J. Anim. Sci. 21:1330-1338.

Yuan, S. L., X. S. Piao, D. F. Li, S. W. Kim, H. S. Lee, and P. F. Guo. 2006. Effects of dietary Astragalus polysaccharide on growth performance and immune function in weaned pigs. Anim. Sci. 82:501-507.

Zhang, L. P., L. Y. Chen, and Y. S. Zhang. 1993. Study on water soluble polysaccharides from Acanthopanax senticosus fruits isolation and purification and structural investigating of AS-2. Chin. J. Biochem. Mol. Biol. 9:1-5. 